\title{
Development of Regional Strategic Framework for Nutrition Action Plan as a tool for Health and Nutrition Diplomacy of the Prevention of Non-Communicable Disease (NCD) in ASEAN Countries
}

\author{
Sugeng Eko Irianto, Yudhinanto
}

University of Mitra Indonesia, Bandar Lampung, Lampung, Indonesia

Email:

ekoindo@gmail.com

Received: October 5, 2020

Accepted: October 14, 2020

Published : November 30, 2020

The trend of prevalence of Non-Communicable Diseases (NCD) such as hypertension, cardiovascular diseases, diabetes mellitus, and cancer has increased for the last few decades among low and midle incomecountries including Indonesia. The purpose in this research is Develop of the document of regional strategic framework for nutrition as part of Health and Nutrition Diplomacy of the Prevention of NonCommunicable Disease in ASEAN Countries. Result of this research are is member countries agree to develop regional strategic framework for nutrition action. Intensive communication among member countries are the key of the development of regional strategic framework for nutrition action plan in order to finalize and improve the quality of the document lead by Ministry of Health in each country. Even though up to date the document of regional strategic framework for nutrition action plan not finalized yet, all member countries believe they will have benefit from the document for future multilateral and bilateral collaboration and as the guidance for health and nutrition diplomacy particularly to prevent non-communicable disease.

Keywords: Strategic framework, nutrition, NCD

Copyright (C) 2020 IIK STRADA Indonesia All right reserved.

This is an open-acces article distributed under the terms of the Creative Commons Attribution-ShareAlike 4.0 International License.

\section{INTRODUCTION}

The trend of prevalence of Non-Communicable Diseases (NCD) such as hypertension, cardiovascular diseases, diabetes mellitus, and cancer has increased for the last few decades among low and midle income-countries including Indonesia. Based on the results of Basic Health Resarch performed in Indonesia in 2013, the prevalence of hypertension was $25.8 \%$, diabetes mellitus was $6.9 \%$, central obesity was $26.6 \%$, and stroke was $1.2 \%$. The cause of NCD is multi-factorial and the main risk factors are high consumption of sugar, salt, and fat, low consumption of vegetables and fruit, overweight, lack of physical activity, and smoking habit.

Lower income countries such as Indonesia are beginning to experience disease patterns like high-income countries, as more processed foods are incorporated into diets in a nutrition transition, with less of the necessary healthcare resources to cope with increased disease burden. Globally, obesity or Body Mass Index (BMI) greater than $30 \mathrm{~kg} / \mathrm{m} 2$ was estimated to have been the cause of 3.4 million deaths in 2010. Excess sugar consumption, particularly consumption of sugar-sweetened beverages (SSBs) is a well- documented, significant causal factor for weight gain. Several studies have found increases in BMI per additional daily serve of SSB and decreases in BMI when SSB consumption is reduced. Excess body mass is a significant risk factor for many NCDs such as ischemic heart disease (IHD), stroke, type 2 diabetes mellitus (T2DM) and various cancers, with the 
associated morbidity and mortality contributing to rising healthcare costs and reduced productivity. Excess sugar consumption directly increases the risk of T2DM, mediated through both the risk due to higher weight and directly through inflammatory mechanisms triggered by elevated blood sugars. the risk of T2DM, mediated through both the risk due to higher weight and directly through inflammatory mechanisms triggered by elevated blood sugars.

In order to intervene and reduce the risks of NCDs, the World Health Organization (WHO) has launched the Global Strategy on Diet, Physical Activity and Health. This strategy urged the government to take actions to reduce the dietary risk of NCDs and increase physical activity and for non-government organizations and private sector to support such measures. There are three food components that are the main targets related to risk of NCDs: sugar, salt, and fat. According to WHO (2015), a high level of intake of free sugars has been associated with poor diet quality, obesity and risk of NCDs. Free sugars, especially in the form of sugar-sweetened beverages, might lead to increased energy intake and reduced intake of more nutritionally balanced foods. Eventually, such intake could bring weight gain and risk of NCDs. Therefore, the organization strongly recommended a reduced intake of free sugars throughout the life course as much as below $10 \%$ of total energy intake, with a conditional recommendation for further reduction to below $5 \%$ of total energy intake.

World Leaders at the Conference on Sustainable Development (Rio+20) reaffirmed the right of everyone to have access to safe and nutritious food, consistent with the right to adequate food and the fundamental right of everyone to be free from hunger. In Rome on November 2014, 170 countries in the world during the second International Conference on Nutrition (ICN2) endorsed action to end all forms of malnutrition. ASEAN Member States adopted of the ASEAN Leaders' Declaration on Ending All forms of Malnutrition during the 31th ASEAN Summit held in November 2017.

On 01 - 05 May 2018 in Philippines, ASEAN Members States through the endorsement of the ASEAN Health Ministers in Philippines and Indonesia have formulated the ASEAN Framework for Nutrition Action Plan. Considering the development of the draft framework is still need action to finalize, therefore Philippines encourage Indonesia as a Co-leader to conduct finalization activity in Indonesia. The activity finalization meeting aims to provide a final document ASEAN Strategic Framework for Nutrition and Action Plan. The document of regional framework of action for nutrition and strategic plan shall guide and strength the ASEAN member States for increasing investment in nutrition. It shall also identify possible areas of cooperation among member states and with dialogue partners and as an instrument of health and nutrition diplomacy to end all forms of malnutrition particularly Non-Communicable Disease in ASEAN Countries.

The purpose in this research is Develop of the document of regional strategic framework for nutrition as part of Health and Nutrition Diplomacy of the Prevention of Non-Communicable Disease in ASEAN Countries.

\section{MATERIALS AND METHODS}

- ASEAN Health Ministers Meeting (AHMM) organized by ASEAN Secretariat;

- High level coordination meeting organized by Ministry of Health and supported by ASEAN Secretariat;

- Share draft document of strategic framework for nutrition action among member's country;

- Technical working group meeting through discussion and brainstorming for finalization organized by Ministry of Health and supported by ASEAN Secretariat;

- Routine virtual discussion;

- Share final draft for member's state clearance and approval;

- Implementation of the health and nutrition diplomacy inter member's country to prevent noncommunicable disease and propose collaboration program intervention on nutrition.

\section{RESULTS AND DISCUSSION}

\section{ASEAN Health Ministers Meeting (AHMM) organized by ASEAN Secretariat}

AHMM hereinafter referred to as Senior Officials Meeting on Health Development (SOMHD). The delegation of the SOMHD consists of Minister, Director General, Director of International Cooperation and some Directors of the Ministry. 
The objective of the meeting was to present of ASEAN's Cooperation Policy in the area of Health Development; Road map of Sustainable Development Goals (SDGs) presentation; situation analysis of health and determinant factors; each country presentation on health problems, program dan possibility cooperation among countries (multilateral collaboration) dan bilateral collaboration follows by discussion dan recommendation for future cooperation. During this meeting all the Senior Official agreed to decide the lead country for certain health program in order to lead and coordinate during the process of the development of strategic frame work.

\section{High level coordination meeting organized by Ministry of Health and supported by ASEAN Secretariat;}

The delegation of the high-level coordination meeting lead by Director General Ministry of Health each country with the member are Director of Related Technical Areas who will collaborate as well as the agenda setting and Director of International Cooperation.

The objective of the meeting was to present of ASEAN's Cooperation Policy in the area of Health Development particularly Public Health problems, Health System Strengthening, Roadmap of Sustainable Development Goals (SDG) 3 and concepts development of Regional ASEAN on Strategic Plan on Nutrition.

The presentation of the propose Regional ASEAN on Strategic Plan on Nutrition by Health Cluster Official of ASEAN Secretariat based on the concept and ideas from the member state follow by discussion and brainstorming among them and decide to develop template as a guidance for the member state to write a draft.

\section{Technical working group meeting through discussion and brainstorming for finalization} organized by Ministry of Health and supported by ASEAN Secretariat;

The delegation of the technical working group meeting through discussion and brainstorming for finalization are Director of Nutrition of the Ministry of Health from each country, Director of Family Health from each country, other related Director to nutrition, Unicef, WHO, Alive \& Thrive, SEAMEO RECFON Indonesia, Director of International Cooperation, Food and Drug Control Authority.

The objective of the meeting was to finalize the draft of ASEAN Strategic Framework for Nutrition Action Plan $2018-2025$.

\section{Summaries of the activities:}

1. Opening remarks, Director of Community of Nutrition

2. Introduction

3. Review Draft ASEAN Action Plan on Nutrition, 2018-2030 (strategic trust 1-2)

4. Review Draft ASEAN Action Plan on Nutrition, 2018-2030 (strategic trust 3-4)

5. Brainstorming:

- Operationalisation of the ASEAN Leaders' Declaration on Ending All Forms of Malnutrition

○ Roadmap SDGs tahun 2017-2030 goal 2 (Nutrition) dan goal 3

- Roadmap SDGs tahun 2017-2030 goal 3 (Reproductive health)) dan goal 5

○ Roadmap SDGs tahun 2017-2030 goal 2 (Agriculture)

6. Site Visit:

○ Welcome remarks from Head of Cinagara Subdistrict

- Welcome remarks from Head of Tangkil Village

- Sharing of experiences on nutrition surveillants implementation: Head of Health Center and Village Volunteer.

7. Review Draft ASEAN Action Plan on Nutrition, 2018-2030 (strategic 5)

8. Brainstorming:

○ WASH presentation:

- Development of a Web GIS-based Nutrition Surveillance System for ASEAN (NSSA)

- Nutrition Surveillance System presentation

9. SEAMEO Recfon Presentation

10. Review of the plan by strategic thrust by sector 
11. Similar activities across sectors were combined and will be led by the health sector, e.g. integration of nutrition in sectoral projects, sharing of good practices, etc.

12. Details of activities by non-health sectors will be verified through the ASEAN Secretariat, e.g. lead countries, timeline, etc.

13. Review of the plan by strategic thrust by sector (cont.) New activities proposed are for consideration for 2021 onwards, unless critical

14. Changes on the draft plan will be shared to other AMS, for concurrence

15. Activities which identified development partners as source of fund will be confirmed from the development partners attending the side meeting

\section{Summary of the agreements}

\section{Matters to be consulted with All Non-Health Sectors:}

- ASEAN Health Cooperation through the Core Group recommended the exclusion of some activities in the proposed Action Plan. ASEAN Health Cooperation highlights that this recommendation does not imply exclusion of such activities in the adopted workplans of the concerned sectoral body.

- Concerned ASEAN sectors to facilitate/coordinate with Lead Countries of proposed activities under their sector in the provision of information to complete the Action Plan.

- ASEAN Health Cooperation, through the Nutrition Contact Points, be consulted in the review of concept papers of project activities led by non-health sectors with a view of ensuring implemented activities are highly nutrition-sensitive.

- Determine the status of implementation of activities with proposed 2017-2018 timelines, and subsequently update information in the Action Plan.

- All activities in Action Plan not currently in the adopted sectoral workplans are recommended to be included in the development of the next sectoral workplans (i.e. 2021-2025 or 2026-2030). New activities could be implemented earlier than 2020 if these are urgent, with identified Lead Countries and Development Partners thatare willing to implement the activities.

\section{Immediate next steps on the finalization of the action plan on nutrition.}

1. ASEAN Secretariat will coordinate with relevant sectoral divisions on Core Group Meeting observations on proposed non-health sector-led activities;

2. Submit the Action Plan on Nutrition for review and endorsement with the ASEAN Health Cooperation:

3. Lead Country Philippines with support from SOMHD Chair Cambodia will communicate with non-health sectors through respective Chairs on

[a] specific inquiries and recommendations on proposed activities

[b] subsequently in getting their concurrence

4. Disseminate to Development Partners and identified key stakeholder

\section{On the proposed ASEAN Nutrition Surveillance System}

1. Agreed that the surveillance system will include core indicators - following global nutrition indicators and including those that are related to the SDG -- that all AMS will collect and report.

2. Output indicators will be finalized as the activities in the Action Plan are endorsed.

3. Partners agreed to share references for the firming up of indicators that will be included in the surveillance system.

4. UNICEF to submit to Lead Country Philippines their feedback, as well as notes, on the draft indicators for consideration of Philippines.

5. Lead Country Philippines will identify proposed core indicators, and subsequently circulate to ASEAN Health Cluster 1 for inputs and feedback.

On the concept notes presented by Philippines on [a] the conduct of a write shop to develop proposals for unfunded project activities in the Action Plan, and [b] the development of GISbased nutrition surveillance system

1. Philippines will revise the concept notes incorporating feedback from the Meeting.

2. The Meeting concurred with the presented concept papers and seek feedback and concurrence 
of ASEAN Health Cluster 1 as proposed activities will form part of the Action Plan on Nutrition.

\section{Routine virtual discussion}

Routine virtual discussion has been done by technical working group to discuss the finalization of the document.

Share final draft for member's state clearance and approval

Share final draft for member's state clearance and approval have been done by ASEAN Secretariat to member state.

Implementation of the health and nutrition diplomacy inter member's country to prevent noncommunicable disease and propose collaboration program intervention on nutrition.

Even though the document still on-going process of finalization by member's countries, the already use for doing health and nutrition diplomacy such as multilateral and bilateral cooperation on the implementation of front of pack (FoP) food and nutrition labeling in order to control the nutrient content of the marketing product in ASEAN Countries particularly salt, sugar and fat.

\section{The component of the Regional Strategic Framework for Nutrition Action Plan:}

- $\quad$ Strategic trust (based on the nutrition problems in each country);

- $\quad$ Project activities 2018 - 2030;

- $\quad$ Expected outputs, output indicators and timelines;

- $\quad$ Change made to make it nutrition sensitive;

- Lead country

- $\quad$ Source of support

REGIONAL STRATEGIC FRAMEWORK FOR NUTRITION ACTION PLAN

\begin{tabular}{ccccc}
\hline PROJECT ACTIVITIES & EXPECTED & CHANGES & LEAD & SOURCE \\
FROM 2018-2030 & OUTPUTS, & MADE TO & COUNTRY & OF \\
& OUTPUT & MAKE IT & & SUPPORT \\
& INDICATORS, & NUTRITION & & \\
& AND & SENSITIVE & & \\
& TIMELINE & & & \\
& & & &
\end{tabular}

STRATEGIC THRUST 1:

WE SUPPORT TO ACCELERATE EVIDENCE-BASED MULTISECTORAL ACTIONS TO

END ALL FORMS OF MALNUTRITION PARTICULARLY AMONG THE MOST

VULNERABLE, POOR AND DISADVANTAGED GROUPS OF ASEAN [SCALING UP NUTRITION SERVICE DELIVERY]

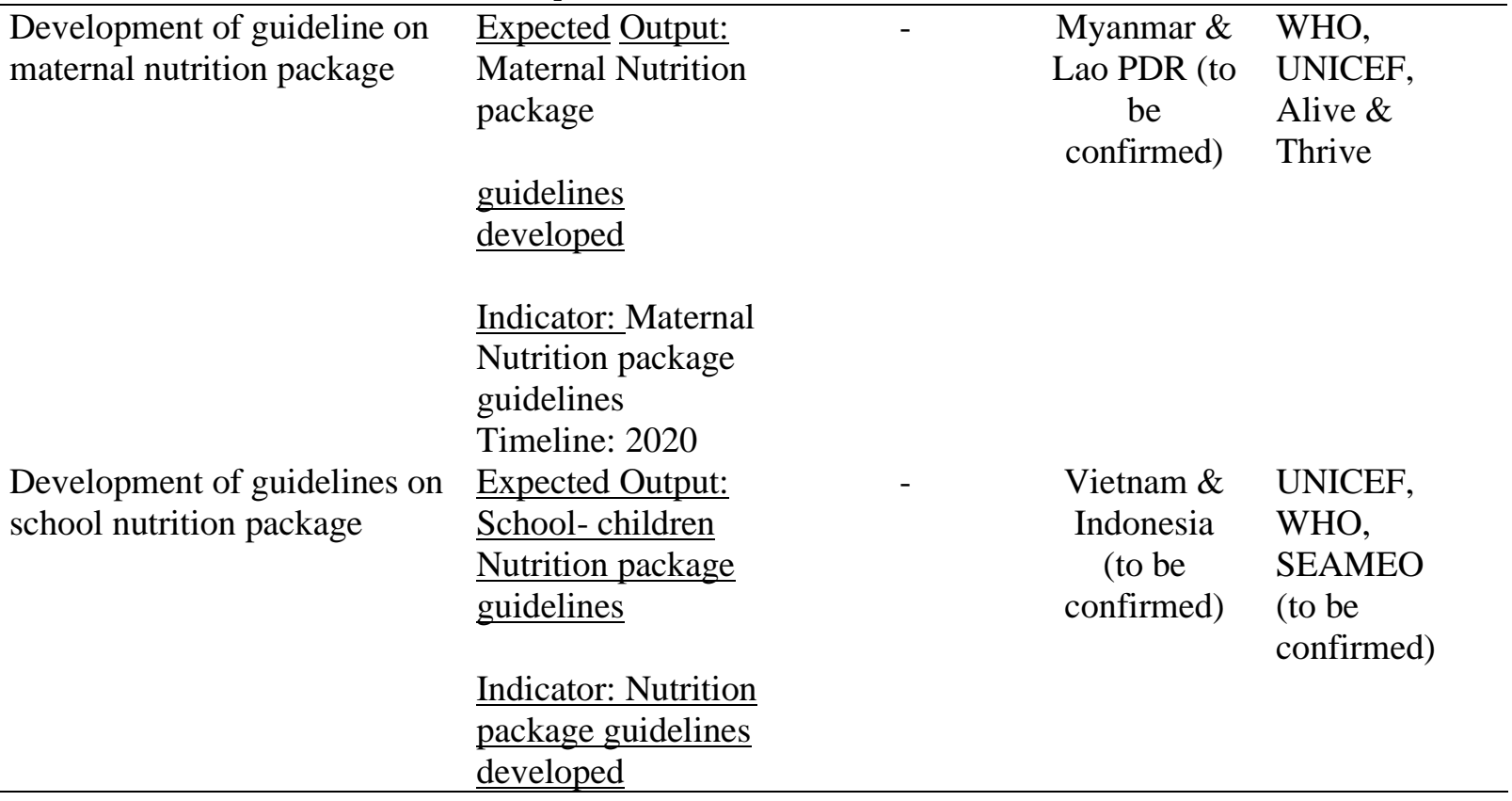


Timeline: 2020

Development of guidelines and minimum standards for the protection, promotion, and support breastfeeding and complementary feeding including the implementation of the code
Expected Output:

Guidelines and

minimum standards

for the protection,

promotion, and

support

breastfeeding and

complementary

feeding including

the

implementation

of the BMS code

Indicator:

Guidelines and

minimum standards

for the protection,

promotion, and

support

breastfeeding and

complementary

feeding, including

the implementation

of the code,

developed

Timeline: 2020

Development of standards for Expected Output:

the implementation of IMAM Standards for the implementation of

IMAM

Indicator: Standards

for the

implementation of

IMAM developed

Timeline: 2020

Expected Output:

guidelines on marketing

food and non-alcoholic beverages to children including:

- Front of pack food and nutrition labeling

- adapt regional nutrient profile model to guide regulations on marketing of food and non-alcoholic
Minimum

guidelines on marketing of food and non- alcoholic beverages to children, including: nutrition

labeling adoption of
Philippines Alive \&

$\&$ Malaysia Thrive,

(to be UNICEF

confirmed)

\section{Cambodia \& UNICEF, Philippines WFP \\ (to be confirmed)}

Philippines WHO, \& Thailand Alive \& Thrive (to be confirmed) 


beverages regional

nutrient

profile model to

guide regulations

on marketing of

food and non-

alcoholic beverages

Indicator:

Minimum

guidelines on

marketing of food

and non- alcoholic

beverages to

children developed

Timeline: $2020-$

$\underline{2021}$

\section{CONCLUSION}

1. All member countries agree to develop regional strategic framework for nutrition action plan refer to country comprehensive strategic plan on nutrition as a guidance of sector related to nutrition to support nutrition activities both specific and sensitive intervention;

2. Intensive communication among member countries are the key of the development of regional strategic framework for nutrition action plan in order to finalize and improve the quality of the document lead by Ministry of Health in each country;

3. Even though up to date the document of regional strategic framework for nutrition action plan not finalized yet, all member countries believe they will have benefit from the document for future multilateral and bilateral collaboration and as the guidance for health and nutrition diplomacy particularly to prevent non-communicable disease.

\section{ACKNOWLEDGMENTS}

The author is thankful for respondents for their valuable information and its awareness to participate in this research

\section{CONFLICTS OF INTEREST}

The author declares that they have no conflict of interest

\section{REFERENCES}

ASEAN Cooperation Strategy for Health Development Plan

Ministry of Development and Planning Republic of Indonesia, Indonesia Medium-term Development Plan, $2015-2019$

Ministry of Health Republic of Indonesia, Strategic Plan for Health, 2015 - 2019

Ministry of Health Republic of Indonesia, Directorate of Community Nutrition, Nutrition Action Plan 2015 2019

Ministry of Health Republic of Indonesia, Directorate of Family Health, Family Health Action Plan 2015 2019

Ministry of Health Republic of Indonesia, Directorate of Non-Communicable Disease, Non Communicable Disease Action Plan 2015 - 2019

Ministry of Health Republic of Indonesia, Directorate of Health Promotion and Community Empowerment, Health Promotion Action Plan 2015 - 2019

Ministry of Health Republic of The Philippines; Lao PDR, Thailand, Myanmar, Malaysia, Cambodia, Vietnam, Singapore, Strategic Plan for Health, 2015 - 2019

World Health Organization (WHO), 2012. Global Strategy on Diet, Physical Activity and Health. 